\title{
Solar Panels Produced Electricity Impact on Electricity Network
}

\author{
P. Shipkovs ${ }^{1}$, G. Kashkarova ${ }^{1}$, K. Lebedeva ${ }^{1}$, L. Migla $^{1}$ and A. Snegirjovs ${ }^{1,2}$ \\ ${ }^{1}$ Institute of Physical Energetics \\ Aizkraukles Street 21, Riga, LV-1006, Latvia \\ Phone/Fax number: +371 67553537, e-mail: shipkovs@edi.lv \\ ${ }^{2}$ Riga Technical University \\ Azenes 16/20, Riga, LV-1048, Latvia \\ Phone: +371 67588633, e-mail: andrejs.snegirjovs@rtu.lv
}

\begin{abstract}
Historically, during the creation of a unified energy system, base load power plants were constructed in Estonia (shale power plants) and Lithuania (the Ignalina nuclear power plant and the Elektrenai power plant). In Latvia, the Daugava hydropower plants were designed for peak, half-peak and emergency modes in which it is possible to relatively quickly and simply implement the sudden increase or decrease of capacity according to necessity. Neither coal nor shale power plants allow such sudden change of generation capacity due to a technologically more complex process.
\end{abstract}

Latvian largest electricity supplier JSC "Latvenergo" $72 \%$ of the electricity - $3.6 \mathrm{TWh}$ (2012) produced from renewable and environmentally friendly energy sources [1]. JSC "Latvenergo" uses two types of energy resources in the energy generation process: renewable energy sources in hydropower plants and in biomass and wind power plants; highly efficient cogeneration in gas-fired power plants.

Latvia already is one of the greener countries in the Europe in accordance with high level of energy production from RES and future strategies for energy sector development also include RES use for heat and electricity production.

The Energy Strategy 2030 sets the following objectives of the energy policy:

- Competitive economy - balanced, efficient, economically, socially, and ecologically justified energy policy based on market principles ensuring further development of the economy, its competitiveness in the region and world;

- Sustainable energy - reduced dependency on imported energy resources, new and efficient technologies for the use of renewable resources are encouraged, measures to improve energy efficiency are implemented;

- Secure supply - stable energy supply and developed infrastructure provided to energy users.

\section{Key words}

Solar panels, electricity production, electricity network.

\section{Introduction}

Taking into account that the renewable energy resources (RES) are very variable and their dependence on many external factors, the increasing RES in proportion of Latvian energy does not only create a positive contribution, but also a lot of negative aspects that need to be solved in order to facilitate the integration of renewable energy. Problems arise mainly in their commitments to the fact that Latvia is not found a solution to balance the state to support successful integration of renewable energy, as well as the unsuitability of the existing infrastructure of new technology features, in particular, problems arise with electricity.

\section{The concept of voltage quality}

Ideal AC electricity supply system voltage (practically designed for all electricity consumers), is characterized by a continuous, sinusoidal function of time at a constant frequency and amplitude. In real conditions a deviations from ideal voltage characteristics consist and as a result power quality for consumers. When deviations of voltage parameters exceed a certain specified limits a wide variety of technical and / or economic losses often appear [2].

In practice, the grid voltage characteristics can be observed in the following variations of deviations:

- Frequency deviation;

- Short-term or long-term amplitude (effective values) deviation;

- $\quad$ Short voltage drops or surges;

- Voltage harmonic disturbances;

- $\quad$ Three-phase system voltage asymmetry;

- $\quad$ Short-term or long-term voltage disturbance [2].

Developed regulations that define the permissible supply voltage parameter variation levels and their duration for 
electricity suppliers are around the world. The standard EN50160 is in force in European public low-voltage and medium voltage networks. Based on EN50160 in Latvia has been developed and is used Latvian Electrotechnical Commission standard LEC 018. Although the standards set voltage quality requirements is the responsibility of the supplier of electricity however, nowadays more and more individual voltage quality technical problems arise due to the electricity users. In order to protect the power grid and ensure that certain equipment safe and high performance in common power grid, for electrical equipment manufacturers and electricity consumers should be restrictions of the distortion level and its impact on the network in the power consumption, depending on network equipment and power relations at the connection point (IEEE 519-1992, IEC 61000-3 -2, etc.) [2].

\section{A. Short-term or long-term voltage level deviation}

The voltage level deviation is usually caused by atmospheric electrical discharge, accidents caused by the transition processes in power grids, high-power electric motor start, poor distribution network configuration or insufficient energy flow control options [2]. In long-term case the line voltage depending on the distance from the power source and the load generation. However, the voltage levels should be maintained in specified range to laws, standards or guidelines for equipment and machinery work in acceptable regimes. On the other hand, when the solar panels output power is greater than the power consumed in use, surplus electricity to flow back into the grid. In this case, power flow changes the direction and voltage increases (Figure 1).

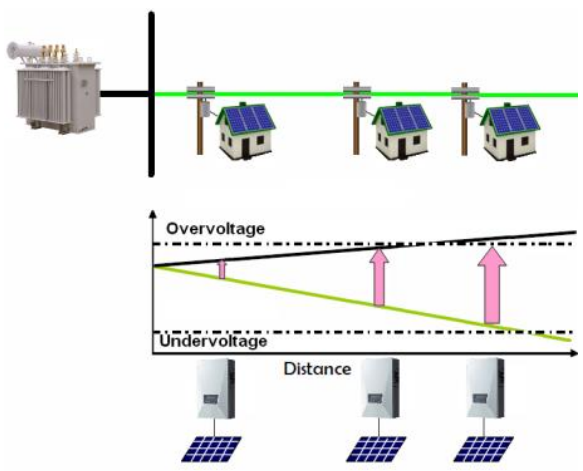

Fig. 1. Overvoltage conceptual diagram.

It's possible to control line voltage by some extent controlled (reduced) voltage transformer substation bar, but it can cause voltage reduction in neighboring lines that are connected to the same bar (Figure 2).

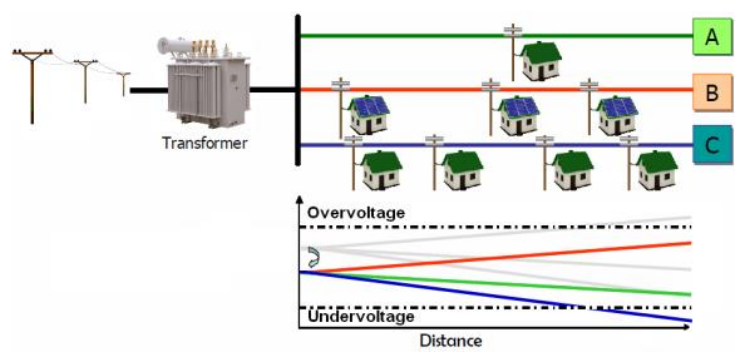

Fig.2. Undervoltage conceptual diagram.
Voltage deflections above than $10 \%$ of the nominal value shortens the life of many electrical equipment's, or even cause irreversible damages. Overvoltage and low-voltage adversely affect the stable operation of supply equipment, including generators and transformers.

The instantaneous voltage change can happen when dispersed generators are connected to the network under certain conditions. For the synchronous generator, a considerable starting current occurs when generators are not correctly synchronized in connection process. Asynchronous machine instantaneous starting current can exceeded nominal current about 5-7 times [3]. Starting current causes the instantaneous voltage decrease in the network.

Solar panels impact on the instantaneous voltage changes is small, because the power fluctuations is relatively slow. The instantaneous voltage change can arise solar panels simultaneous cut-off in the case of oversensitive inverter protection triggered unplanned of isolated system and disclose solar panels of the line occurrence (Figure 3, 4).

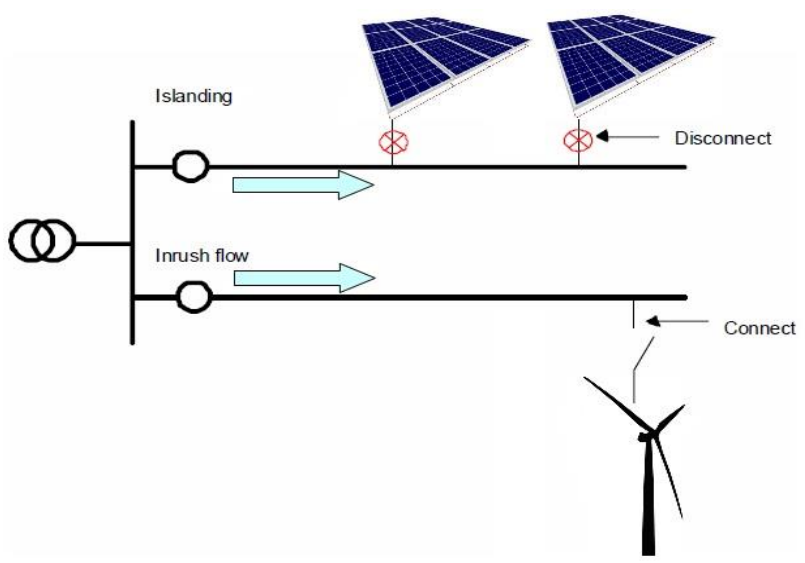

Fig. 3. The instantaneous voltage change due to diffused generation.

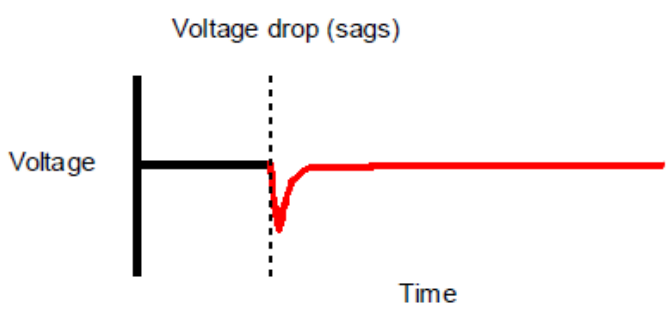

Fig. 4. The instantaneous voltage time diagram.

Computers, office automation equipment and industrial robots are sensitive to the instantaneous voltage changes. Even levels within $\pm 10 \%$ of the nominal value of the voltage deflection may degrade electrical equipment operation mode, creating a sub-optimal reactive power flows, voltage levels affect stable operation of consumer equipment. 


\section{B. Voltage harmonic distortion of electric network}

Voltage asymmetry is a condition in which a three-phase system, each phase voltage amplitude value is different or the angle between the phases is not exactly $120^{\circ}$ (Figure 5). Load asymmetry or feeding from solar system of threephase system causes the voltage asymmetry between phases and, which generate: power with dual frequency and opposite magnetic field in three-phase synchronous machines; have a negative impact on the generators by increasing temperature of the rotor, vibration and noise. It will also affects the asynchronous generators and power electronics equipment.

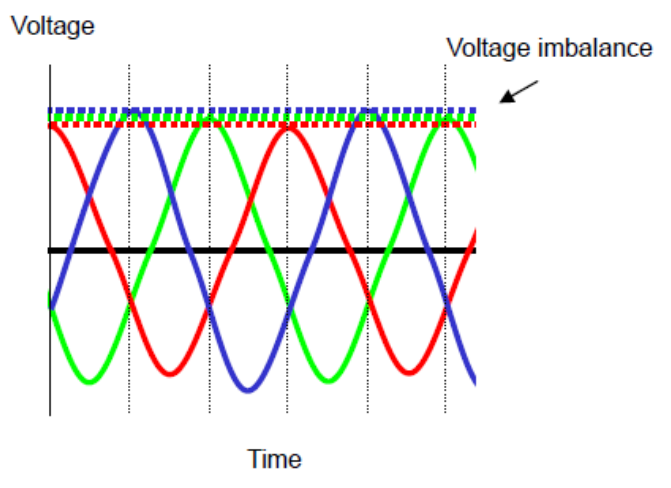

Fig. 5. Voltage imbalance.

The larger non-symmetric can cause components overheating, especially engines and intermittent shutdown engine controllers. Engine operating on asymmetry can overheat and many overload relays cannot feel overheating. In addition, solid-state motor's controllers and inverters often contain parts that are particularly sensitive to the voltage asymmetry.

Harmonic wave is defined as the frequency component of the signal with a higher frequency compared to the base frequency of the integer. In the process of alternating current conversion to the desired current wave electronic devices create harmonics that distort network sinusoidal wave, as shown in the Figure 6.

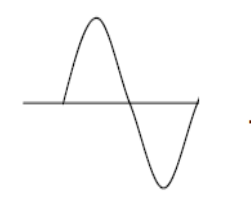

Fundamental waveform

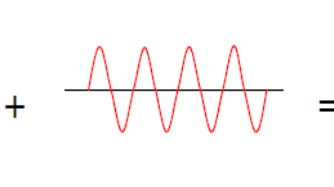

Harmonics

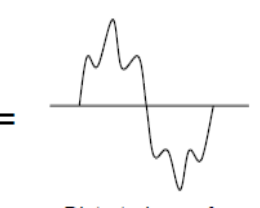

Distorted waveform
Fig. 6. Sinusoidal distortion.

Voltage harmonic distortion is mainly caused the network of electrical magnetic system overload or large nonsinusoidal load currents. Non-sinusoidal load currents often cause different power electronic converters in modern industrial and household electrical appliances are becoming increasingly popular [2]. Network voltage harmonic distortion can also cause a sufficiently large number of low power consumers, such as solar panels inverters convert the direct current to alternating current through a semiconductor switching scheme, and the resulting $\mathrm{AC}$ wave is not an ideal sinusoidal wave. The new inverter models have few harmonics (Figure 7), but the older, poorer quality inverters may incur higher harmonics converted into outlet AC.

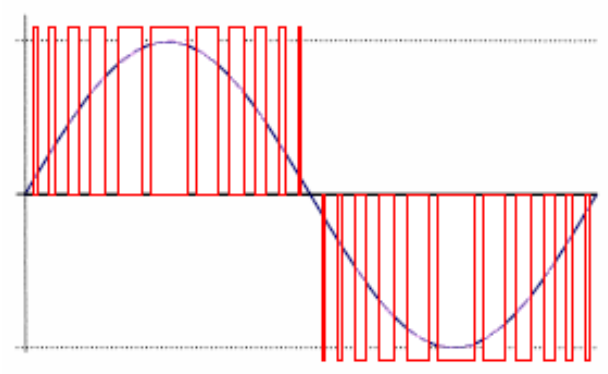

Fig. 7. Use of impulse width modulation for harmonics reduction.

Harmonics affect operation of the consumer's equipment: elevators vibration, TV and daylight flashing, sound quality disturbance and control equipment malfunctions. If a malfunction occurs with the odd harmonics 3.5 or 7 , they can cause a lot current value in the neutral conductor. If the wire is with smaller cross-section compared to active wires, it may be overheated.

In order to control the harmonic voltage distortion level electric networks for consumers it is necessary to limit current distortion by controlling the load and limiting the voltage harmonics of power supply companies, by controlling the impedance of the power system. According to the Cabinet Regulations Nr.793 "Electricity Trade and Use Rules" electricity user pays for consumed reactive energy and for operator transferred to the network reactive energy in Latvian Republic, but these regulations are not include the conditions of an issued current harmonic distortion [4]. While the following conditions are not, consumers are not interested in improving of the consumed power quality, and sometimes all of voltage quality problems blamed only electricity suppliers [2].

\section{Generation of isolated system}

Isolated system arising is the electrical phenomenon in which solar system in the network continues to deliver energy to the network, even when part of the network is disconnected from the main network for some reason. If part of the network is disconnected from the main network, solar panels system is designed to identify abnormal quality of power voltage, frequency and network resistance and immediately disconnect it from the network. However, if the solar system output power will be identical to consumed load, the protection system will not be able to detect the occurrence of isolated systems and to continue power supply.

It should be noted that the isolated system the probability is relatively low, due to the isolated system arising the impact on the power grid is small. 


\section{A. Short-circuit power}

Short-circuit power is a parameter that represents the electrical current level in case of short-circuit. If the number of distributed generators connected to the distribution line, the short-circuit current may exceed the estimated level. If the short-circuit current is higher than the power switch, the switch will not disable the shortcircuit current, and network equipment will be damaged (Figure 8). Solar system impact is not as decisive importance in comparison to synchronous generators, since for all inverters with international standards for grid connection, overload protection is installed (runs at 1.1 to 1.5 times higher of short-circuit currents compared to the nominal current), which immediately disconnected systems.

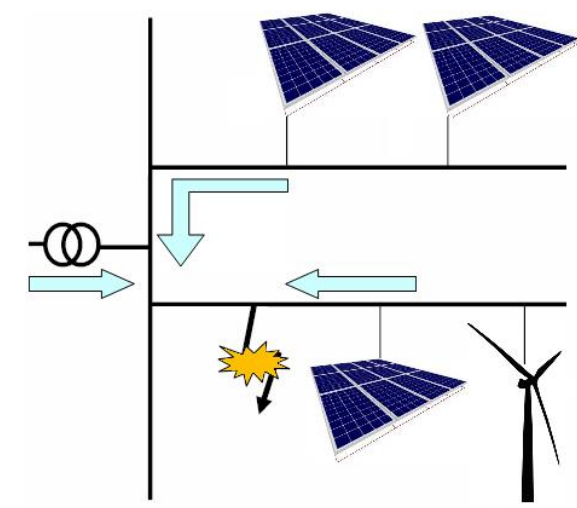

Fig. 8. Conceptual diagram of the short-circuit capacity.

\section{B. Internal damage shutdown time}

High-voltage and low voltage windings are isolated from one another in transformers. The isolation damage, which can lead to internal damage to the transformer can occur overvoltage case (lightning discharge) (Figure 9). In case of internal damage, power plant should stopped work and power must be disconnected from the network. However, the solar panels system cannot detect this damage, the substation switches does not open and the isolated system arises. Investigations shows that the solar panels system shutdown time takes too much time.

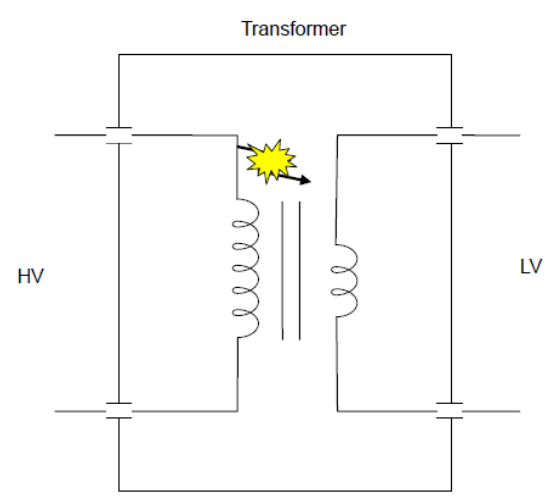

Fig. 9. Transformer internal damage

\section{Frequency variations}

Keep the electricity is difficult, both economically and physically, but on the other hand it is necessary to supply power to meet demand fluctuations. Imbalance between supply and demand leads to frequency fluctuations. Frequency is one of the most important factors of power quality and shall remain the same throughout the network. With a production capacity increase from uncontrolled energy sources (wind and sun) becoming harder to control power quality. Power fluctuations from the solar system are much smaller than from wind turbines. However, the frequency deviation issues become noticeable by the increasing of the number of solar panels connections.

Inverters using high-frequency $10-20 \mathrm{kHz}$ to convert direct current to alternating current. It is predicted that electromagnetic waves incurred from the inverter and are transmitted through the air and electrical cables have a negative impact on other electronic devices. It is reciprocal electromagnetic wave effect of the electronic devices in homes and offices, as well as solar panels inverters. Solar inverter electromagnetic waves affect the communications and IT equipment such as TV and radio, and vice versa.

\section{Solutions for the network voltage quality improvement}

The network voltage quality issues in the problematic network segments primarily solved by increasing the installed supply capacity and improving grid topology. Voltage levels and harmonic distortion problems in the world today deal with the various so-called "Smart grid" technology, which is based on power electronic converters - semiconductor energy flow regulators, active filters, etc.

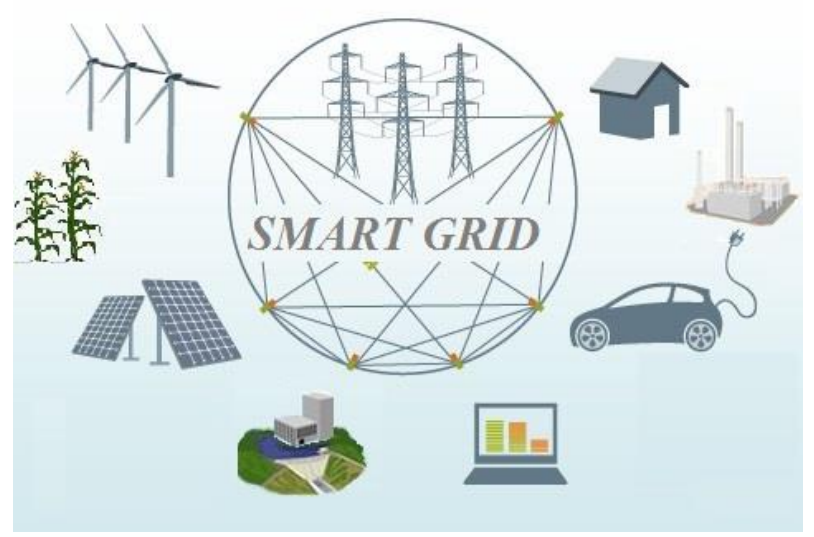

Fig. 10. Smart grid.

\section{Conclusion}

Riga CHPs of JSC "Latvenergo" - the main electricity producer in Latvia provided $1.41 \mathrm{TWh}$ or a sixth part of the Latvian electricity consumption. The rest of the state consumption ensured the Daugava hydropower plants 
(3.63 TWh). Another electricity producers provided 1.08 TWh. and imported electricity (1.3 TWh or $17 \%$ from total electricity supply) in 2012 and electricity supply from RES was $0.5 \mathrm{TWh}$.

Traditionally with electricity network has been a radial structure with a one-way energy flow. Thus, the development of distributed power generation and electricity market liberalization, the situation is changing rapidly. The distribution network losing the radial structure and it optimization and stable functioning becomes increasingly complex. Stable and safe electricity supply will require technology and regulations that govern the variable and unpredictable energy flow in the future electricity network and in distributed power generation conditions it is important to use modern power electronics.

Will have to reckon with the fact that every year the number of electricity producers using RES for electricity production and which will be connected to the network will be larger and must be monitored all the laws and regulations of the network connection has been completed accurately.

\section{Acknowledgement}

This work has been supported by State Research Program "LATENERGY".

\section{References}

[1] http:// latvenergo.lv/ lat / par_mums /isuma_par /vides_aizsardziba/. (In Latvian)

[2] O.Krievs „Sprieguma kvalitāte”. Konference "Latvenergo koncerna attīstība. Brīvā tirgus apstākḷos", 07.11.2012. (In Latvian)

[3] P.Shipkovs, V.Bezrukov, V.Pugachev, Vl.Bezrukov, V.Silutins. „Research of the wind energy resources distribution in the Baltic region". Renewable Energy an International Journal No 49 (2013), Elsever, 119-123 pp.

[4] P.Shipkovs, G.Kashkarova, I.Purina, K.Lebedeva, M.Pankars, J.Shipkovs, K.Grinbergs „Latvian Legislative Impact on the Use of RES in Latvia" World Renewable Energy Forum 2012, Denver, Colorado, May 13-17, 2012. 3396-3409 pp. 